\title{
Comparison of RBG-banded karyotypes of cattle, sheep and goat
}

\author{
H Hayes, E Petit \\ Institut National de la Recherche Agronomique, \\ Laboratoire de Cytogénétique, CRJ, 78350 Jouy-en-Josas, France
}

(Proceedings of the 9th European Colloquium on Cytogenetics of Domestic Animals; Toulouse-Auzeville, 10-13 July 1990)

cattle / goat / sheep / RBG-bands / chromosomes

Based on natural taxonomic criteria, the 3 main domestic species of the Bovidae family belong to 2 different subfamilies: Bovinae (Bos taurus: domestic ox or cattle) and Caprinae (Capra hircus: goat, Ovis aries: domestic sheep).

Cattle, goat and sheep karyotypes show a high degree of similarity as far as their nombre fondamental $N F=58$ (number of autosome arms) and the band patterns of most of their chromosome arms are concerned (Buckland and Evans, 1978; Di Berardino et al, 1987; Mensher et al, 1989).

Only small differences in the band patterns have been reported between goat and sheep, on the one hand, and cattle, on the other, for autosome 9 and for the sex chromosomes (Ford et al, 1980; ISCNDA, 1989).

In this study, we have investigated in greater detail these differences using synchronized cultures of primary embryo fibroblasts and the RBG-banding technique.

To obtain a high yield of metaphase and early metaphase cells, cultures of primary embryo fibroblasts were synchronized with a double thymidine block of S phase (Viegas-Pequignot and Dutrillaux, 1978, and personal communication).

Harvest, hypotonic treatment, fixation and spreading of cells and fluorescence plus Giemsa (FPG)-staining are described in Viegas-Pequignot et al 1989. Chromosomes were numbered according to ISCNDA 1989.

A band-by-band analysis of the RBG-banded chromosomes of sheep, goat and cattle clearly showed the high degree of conservation of their banding pattern; the only differences which we consistently observed concern autosome 9 and sex chromosomes.

Figure 1 shows sheep, goat and cattle autosomes 9 from different karyotypes chosen for their characteristic banding. Sheep and goat autosomes 9 appear identical at this level of resolution but differ from that of cattle. We found that the pale region 
located in about the middle of this chromosome was lower in cattle than in goat and sheep and that the number of bands below this region was higher in goat and sheep than in cattle, while that above this region was smaller in goat and sheep than in cattle. This leads us to suggest that a paracentric inversion, as indicated in figure 1, may have occurred when Bovinae and Caprinae diverged. However, it will be necessary to obtain even finer banding patterns and/or to use specific probes of this region in in situ experiments to verify this hypothesis.

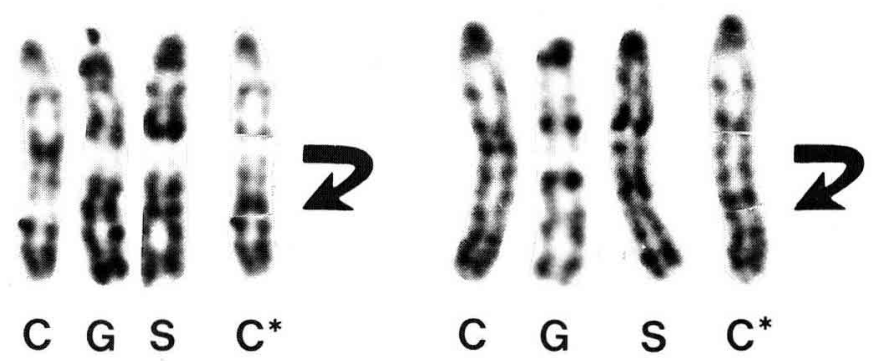

Fig 1. Comparison of goat (G), sheep (S) and cattle (C) RBG-banded autosomes 9. The proposed paracentric inversion leading to cattle autosome 9 is indicated by an arrow. $\mathbf{C}^{*}$ is a montage of cattle autosome 9 with its central region inverted.

Figure 2 contains $\mathrm{Y}$ and X RBG-banded chromosomes. Figure 2 a presents the $\mathrm{Y}$ chromosomes and, as previously reported, in sheep and goat they looked identical, very small, acrocentric with darkly stained $\mathrm{p}$ arms, while in cattle, they were larger, submetacentric and almost entirely pale except in the p arm.

Figure $2 \mathrm{~b}$ shows $\mathrm{X}$ chromosomes for the 3 species from various karyotypes. As for $\mathrm{Y}$ chromosomes, we found that sheep and goat had identical $\mathrm{X}$ chromosomes while cattle were quite different. We did not observe the difference in the q terminal region that Mensher et al (1989) saw after G-banding.

However, as reported by Di Berardino et al (1987) for goat and cattle, we also found that a large portion of the $\mathrm{q}$ arm of goat and sheep $\mathrm{X}$ chromosomes closely resembled the $q$ arm of the cattle $X$ chromosome, if the latter were turned upside down as shown in figure $2 \mathrm{~b}$. The remaining regions of this chromosome cannot be easily matched with those of goat and sheep $\mathrm{X}$ chromosomes, therefore it is probable that a complex series of events occurred between the ancestral form of the Bovidae $\mathrm{X}$ chromosome considered to be close to the goat type and the actual cattle type. Indeed, the fact that a large portion of the banding pattern was found to be common in all 3 species is in agreement with Ohno's (1969) hypothesis that the $\mathrm{X}$ chromosome has been preserved in toto from a common ancestor in many mammalian species.

\section{ACKNOWLEDGMENTS}

We thank B Dutrillaux for helpful discussions. 

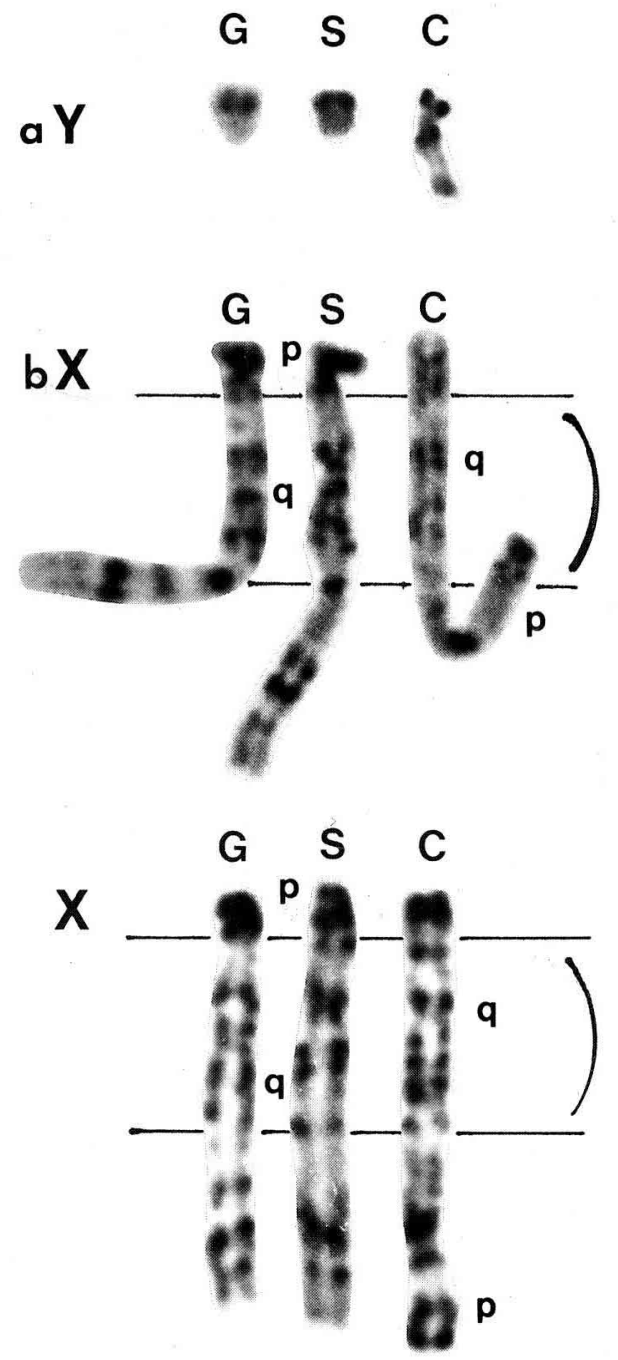

Fig 2. Comparison of goat (G), sheep (S) and cattle (C) RBG-banded Y (a) and X (b) chromosomes. The proposed common region in the $\mathrm{X}$ chromosome of these 3 species is indicated by a parethesis.

\section{REFERENCES}

Buckland RA, Evans HJ (1978) Cytogenetic aspects of phylogeny in the Bovidae. I. Gbanding. Cytogenet Cell Genet 21, 64-71

Di-Berardino D, Rønne M, Burguete I, Lioi MB, Taibi L, Matassino D (1987) R-banding pattern of the prometaphase chromosomes of the goat. $J$ Hered $78,225-230$ 
Ford CE, Pollock DL, Gustavsson I (1980) Proceedings of the first International Conference for the Standardisation of Banded Karyotypes of Domestic Animals. Hereditas 92, 145-162

ISCNDA 1989 (1990) International System for Cytogenetic Nomenclature of Domestic Animals. (Di Berardino D, Hayes H, Fries R, Long S, eds) Cytogenet Cell Genet 53, 65-79 Mensher SH, Bunch TD, Maciulis A (1989) High-resolution G-banded karyotype and idiogram of the goat: a sheep-goat G-banded comparison. J Hered 80, 150-155

Ohno S (1969) The mammalian genome in evolution and conservation of the original $\mathrm{X}$-linkage group. In: Comparative Mammalian Cytogenetics (Benirschke K, ed) SpringerVerlag, New York, 18-29

Viegas-Pequignot E, Dutrillaux B (1978) Une méthode simple pour obtenir des prophases et des prométaphases. Ann Génét 21, 122-125

Viegas-Pequignot E, Dutrillaux B, Magdelenat H, Coppey-Moisan M (1989) Mapping of single-copy DNA sequences on human chromosomes by in situ hybridization with biotinylated probes: enhancement of detection sensitivity by intensified-fluorescence digitalimaging microscopy. Proc Natl Acad Sci USA 86, 582-586 